\title{
Nosocomial Legionnaires' disease: Clinical and radiographic patterns
}

\author{
Thomas J Marrie, MD, DAVID Haldane, MB, Gregory BezAnson, PhD
}

\begin{abstract}
TJ Marrie, D Haldane, G Bezanson. Nosocomial Legionnaires' disease: Clinical and radiographic patterns. Can J Infect Dis 1992;3(5):253-260. From 1981 to 1991 , 55 patients (33 males, 22 females, mean age 58.6 years) with nosocomial Legionnaires' disease were studied. The mortality rate was $64 \%$. One-half of the patients developed nosocomial Legionnaires' disease within three weeks of admission. A surprising clinical feature was the low rate of findings of consolidation on physical examination, despite the fact that $52 \%$ of patients had this finding on chest radiograph. More than one-half of patients had pre-existing lung disease, rendering a radiographic diagnosis of pneumonia due to Legionella pneumophila impossible in 16\% of cases despite microbiological confirmation. Nineteen per cent of patients who had blood cultures done had a pathogen other than $L$ pneumophila isolated, suggesting dual infection in at least some of the patients. When the clinical and radiographic findings were combined it was noted that $40 \%$ of patients had one of three patterns suggestive of nosocomial Legionnaires' disease: rapidly progressive pneumonia, lobar opacity and multiple peripheral opacities. However, in $60 \%$ of patients there were no distinctive features.
\end{abstract}

Key Words: Legionnaires' disease, Nosocomial

\section{Maladie du légionnaire nosocomiale: modèles cliniques et radiographiques}

RÉSUMÉ: De 1981 à 1991, 55 patients (33 de sexe masculin et 22 de sexe féminin: moyenne d'âge: 58.6 ans) atteints d'une maladie du légionnaire nosocomiale ont été observés. Le taux de mortalité a été de $64 \%$. La moitié des patients ont développé une maladie du légionnaire nosocomiale dans les trois semaines suivant leur admission. Il a été surprenant de constater la faiblesse des taux de corroboration des résultats à l'examen physique, en dépit du fait que $52 \%$ des patients présentaient des signes à la radiographie pulmonaire. Plus de la moitié des patients présentaient une maladie pulmonaire pré-existante qui rendait impossible le diagnostic radiographique de pneumonie attribuable à Legionella pneumophila dans $16 \%$ des cas, malgré une confirmation microbiologique. Dix-neuf pour cent des patients chez qui ont avait fait des hémocultures présentaient un autre organisme pathogène que $L$ pneumophila, suggérant une double infection chez certains d'entre eux. Lorsque les résultats cliniques et radiographiques ont été combinés, on a pu noter que $40 \%$ des patients présentaient l'un des trois modèles associés à la maladie du légionnaire nosocomiale, une opacité lobulaire de pneumonie à progression rapide et de multiples opacités périphériques. Cependant, chez $60 \%$ des patients, aucune caractéristique distinctive n’a été notée.

Departments of Medicine and Microbiology. Dalhousie University: and the Victoria General Hospital. Halifax. Nova Scotia Correspondence and reprints: Dr TJ Marrie, Room 4090 ACC. Victoria General Hospital, 1278 Tower Road. Halifax, Nova Scotia B3H 2 Y9

Received for publication May 6, 1991. Accepted August 9, 1991 
$S^{3}$ HORTLY AFTER ITS ISOLATION IN 1977 (1) IT BECAME EVIdent that Legionella pneumophila caused nosocomial pneumonia (2-7). Its adaption to an aquatic ecological environment has led, in part, to its success as a nosocomial pathogen (8-10). Contaminated potable water has been shown to be a source of legionella in many hospitals (11-14), and eradication of the microorganism from the water supply has resulted in cessation of outbreaks (14). Despite many descriptions of the epidemiology of nosocomial legionellosis (11-14), there have been very few studies that have tried to characterize distinctive clinical presentations of this form of nosocomial pneumonia.

The authors have identified cases of nosocomial Legionnaires' disease at their institution since 1981. In the present paper they describe their experience with 55 cases of this illness and emphasize recognition of its different clinical presentations.

\section{MATERIALS AND METHODS}

Case detection: From 1983 to 1987 (15) the present authors performed serological testing for $L$ pneumophila on all patients with nosocomial pneumonia. In addition. from 1981 to 1991, patients with nosocomial pneumonia have been investigated for $L$ pneumophila at the discretion of their attending physicians and infectious disease consultants. Knowledge of the presence of legionella in the hospital's potable water is widespread and prompts efforts to identify cases of nosocomial Legionnaires' disease. Using the definitions given below, 55 cases of nosocomial Legionnaires' disease were diagnosed. Forty of these were studied prospectively. Data on the remainder were collected through a retrospective chart review. For each patient, the symptoms present at onset of pneumonia were recorded.

Case definition: Legionnaires' disease was diagnosed if one or more of the following criteria were fulfilled: L pneumophila isolated from respiratory secretions, pulmonary tissue or pleural fluid; acute and convalescent serum samples with at least a fourfold rise in antibody

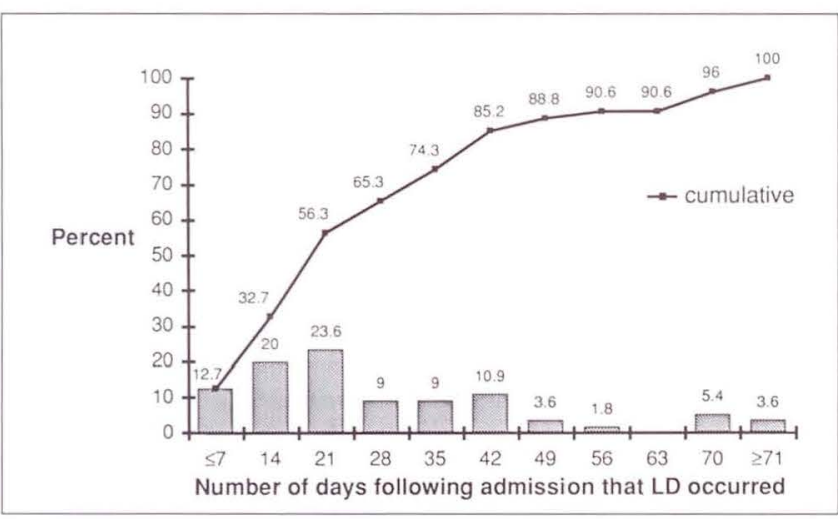

Figure 1) Number of days after admission to hospital that nosocomial Legionnaires' disease (LD) was diagnosed. The percentage at various time intervals as well as the cumulative percentage is shown
TABLE 1

Symptoms and signs in 55 patients with nosocomial Legionnaires' disease

\begin{tabular}{lc}
\hline Symptoms & Number (\%) \\
\hline Fever & $41(75)$ \\
Cough & $37(67)$ \\
Dyspnea & $35(64)$ \\
Chills & $17(31)$ \\
Nausea & $12(22)$ \\
Vomitting & $12(22)$ \\
Diarrhea & $12(22)$ \\
Pleuritic chest pain & $8(15)$ \\
Signs & \\
Mean temperature $\left({ }^{\circ} \mathrm{C} \pm \mathrm{SD}\right)$ & $38.74 \pm 1.28$ \\
Mean respiratory rate $(\mathrm{per}$ min $\pm \mathrm{SD})$ & $24.22 \pm 11.6$ \\
Mean pulse rate $($ beats/min \pm SD) & $108.4 \pm 20.87$ \\
Rales & $44(80)$ \\
Rhonchi & $13(24)$ \\
Bronchial breathing & $9(16)$ \\
\hline
\end{tabular}

TABLE 2

Potential risk factors in 55 patients with nosocomial Legionnaires' disease

\begin{tabular}{lc}
\hline Feature & Number (\%) \\
Corticosteroid therapy & $38(69)$ \\
Antibiotic therapy prior to onset of & $34(62)$ \\
pneumonia & \\
Assisted ventilation & $33(60)$ \\
Surgery within two weeks of pneumonia & $29(53)$ \\
$\quad$ onset & $16(29)$ \\
Malignancy & $16(29)$ \\
Tobacco smoker & $15(27)$ \\
No immunosuppressive therapy & $11(20)$ \\
Aspiration observed &
\end{tabular}

titre to at least 1:128 (a high stable titre or a single high titre were not accepted as evidence of Legionnaires' disease); or a positive direct fluorescent antibody test for $L$ pneumophila in respiratory secretions or post mortem lung tissue.

Isolation of $\boldsymbol{L}$ pneumophila: Material (sputum, endotracheal secretions, pleural fluid or lung tissue) for culture was inoculated onto 5\% sheep blood agar; buffered charcoal yeast extract agar (BCYE) containing $0.1 \%$ alpha-keto-glutarate and two selective media (one BCYE containing cefamandole, polymixin B and anisomycin and the other BCYE containing polymixin B, anisomycin and vancomycin [Gibco Laboratories, Wisconsin]). All plates were incubated aerobically at $37^{\circ} \mathrm{C}$ in a humidified atmosphere containing $5 \%$ carbon dioxide for seven days and examined daily. Colonies that morphologically resembled legionella were cultured onto blood and BCYE agar. Those that failed to grow on blood agar were examined by a direct fluorescent antibody technique (16) using $L$ pneumophila serogroup 1 
antisera (Centers for Disease Control in Atlanta, Georgia).

Direct fluorescence antibody studies for $L$ pneumophila: Endotracheal secretions, lung tissue and pleural fluid were examined for $L$ pneumophila serogroups 1 to 6 using the direct fluorescent antibody technique described by Cherry et al (16).

Antibody titres to $L$ pneumophila: Antibody titres to $L$ pneumophila serogroup 1 were performed on acute and convalescent serum samples using an indirect fluorescent antibody technique (17). Positive and negative controls were included with each run. All reagents for this test were obtained from the Centers for Disease Control in Atlanta, Georgia

Review of chest radiographs: All 55 patients had pneumonia diagnosed radiographically by a radiologist. Fifty had chest radiographs available at the end of the study; these were reviewed by one of the authors during July and August 1990 in order to correlate radiographic patterns with clinical presentation. Rapidly progressive pneumonia was defined as an increase in the size of the opacity at least $50 \%$ in $48 \mathrm{~h}$. Chronic obstructive pulmonary disease, pulmonary edema, pulmonary hemorrhage and interstitial fibrosis were diagnosed on the basis of a combination of clinical and radiological criteria. Chronic obstructive pulmonary disease is strictly a clinical rather than a radiological diagnosis. This term was used when the chest radiograph demonstrated flattening of the diaphragm and increased anteriorposterior diameter of the chest.

\section{RESULTS}

Fifty-five patients (33 males and 22 females; mean age 58.6 years) had nosocomial Legionnaires' disease diagnosed from 1981 to June 1990. Thirty-five (64\%) died. The diagnosis was made by: isolation of the microorganism (40); positive serology (12); direct fluorescent antibody test (three). Thirty-eight of the isolates were $L$ pneumophila serogroup 1, one was serogroup 6 and one was Legionella micdadei.

Just over one-half of the patients (56.3\%) acquired Legionnaires' disease within three weeks of hospitalization (Figure 1); however, two patients had been hospitalized for more than 71 days before they acquired Legionnaires' disease. The symptoms and signs that these patients exhibited are given in Table 1. Selected demographic features are given in Table 2. Of note is the large number of patients who were receiving corticosteroid therapy $-69 \%$. An additional 16\% received some other form of immunosuppressive therapy. Twenty-nine per cent had a malignancy and 60\% required assisted ventilation. Observed aspiration was surprisingly common, affecting $20 \%$ of patients.

Results of blood cultures are given in Table 3 . Twenty-eight per cent of those who had blood cultures done had a pathogen isolated. Staphylococcus aureus was most common, followed by Escherichia coli. A vari-
TABLE 3

Results of blood cultures in 55 patients with nosocomial Legionnaires' disease

\begin{tabular}{lc}
\hline & Number (\%) \\
\hline Number who had blood cultures done & $47(85)$ \\
Negative culture & $34(72)$ \\
Staphylococcus aureus & $4(8.5)$ \\
Escherichia coli & $2(4.2)$ \\
Streptococcus pneumonia & $1(2.1)$ \\
Streptococcus mitis & $1(2.1)$ \\
Haemophilus influenzae & $1(2.1)$ \\
\hline
\end{tabular}

TABLE 4

Results of sputum cultures and special stains for pathogens other than legionellaceae in 55 patients with nosocomial Legionnaires' disease

\begin{tabular}{lc}
\hline & Number (\%) \\
\hline Sputum cultures done & $52(95)$ \\
Staphylococcus aureus & $12(23)$ \\
Candida albicans & $9(17.3)$ \\
Pseudomonas aeruginosa & $6(11.5)$ \\
No growth & $6(11.5)$ \\
Escherichia coli & $5(9.6)$ \\
Proteus mirabilis & $5(9.6)$ \\
Kleibsiella species & $4(7.7)$ \\
Citrobacter species & $3(5.8)$ \\
Enterobacter species & $2(3.8)$ \\
Acinetobacter species & $1(1.9)$ \\
Streptococcus pyogenes & $1(1.9)$ \\
Streptococcus pneumoniae & $1(1.9)$ \\
Enterococcus fecalis & $1(1.9)$ \\
Pneumocystis carinii & $1(1.9)$ \\
\hline
\end{tabular}

TABLE 5

APACHE score* and mortality in 51 patients with nosocomial Legionnaires' disease

\begin{tabular}{lcc}
\hline Score & Number who lived & Number who died (\% total) \\
\hline 0 to 9 & 2 & $1(33)$ \\
10 to 14 & 6 & $5(46)$ \\
15 to 19 & 5 & $10(66)$ \\
20 to 29 & 5 & $16(76)$ \\
30 to 34 & 0 & $1(100)$ \\
\hline
\end{tabular}

*Refer to reference 18

ety of microorganisms was isolated from respiratory secretions (Table 4). Eleven per cent of the sputum samples showed no growth. Staph aureus was isolated from 23\% of patients. Fifty per cent had an aerobic Gram-negative microorganism isolated. The authors were unable to distinguish colonization from infection. Table 5 correlates the APACHE score (18) with mortality. While the numbers in each category are small, there is an increase in mortality with increasing score.

A comparison of patients who lived with those who died revealed that those who died were more likely to 


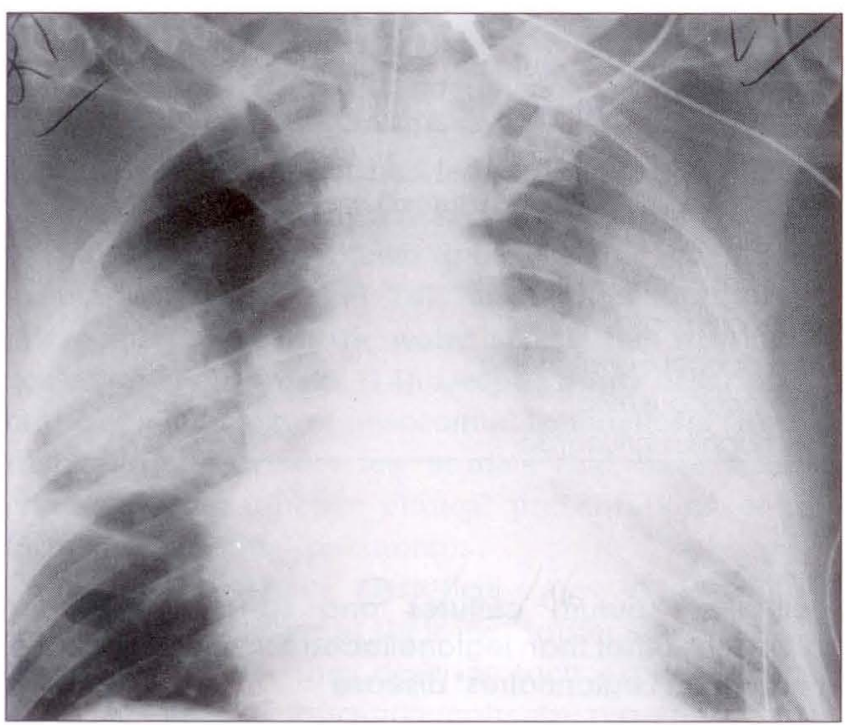

Figure 2) Lobar type pneumonia due to Legionella pneumophila. This patient also fulfilled the criteria for rapidly progessive penumonia

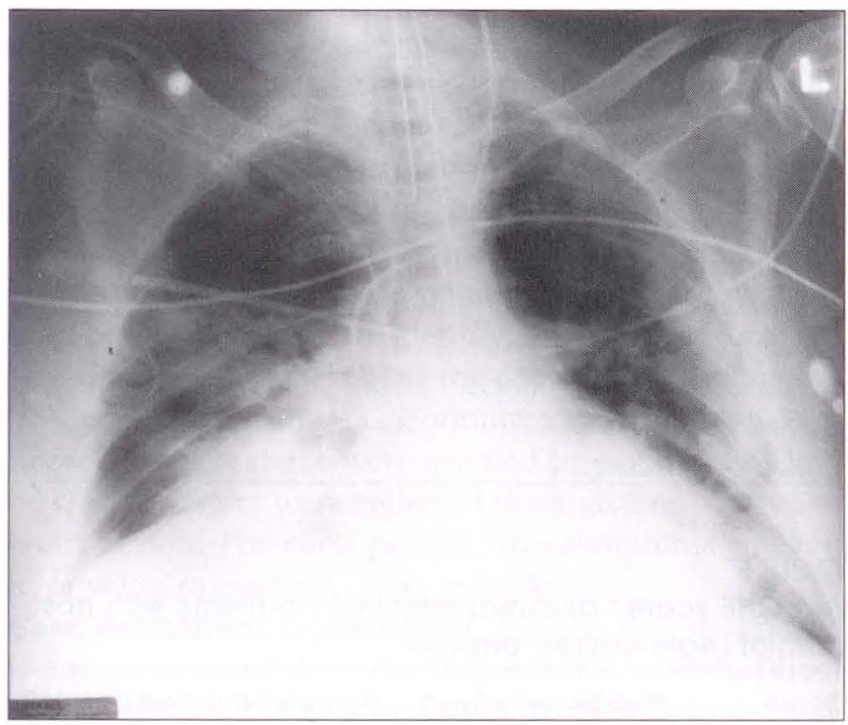

Figure 3) Chest radiograph of a patient with nosocomial Legionnaires' disease with multiple peripheral and rounded opacities

have legionella isolated (29 of 35 versus nine of 20 $[\mathrm{P}<0.01])$ and to have rapidly progressive or lobar pneumonia ( 17 of 35 versus two of $20[\mathrm{P}<0.01]$ ).

Twenty-six of the 50 patients $(52 \%)$ who had chest radiographs available for review at the end of the study showed consolidation. Patchy opacities were present in $15(30 \%)$ and rounded opacities were seen in eight (16\%). Diffuse alveolar disease was present in eight $(16 \%)$ and a pleural effusion in five $(10 \%)$. Cavitation was observed in two (4\%). A major finding was the presence of pre-existing lung disease in 29 patients (58\%). Chronic obstructive pulmonary disease was most common (14 or $48 \%$ ), followed by interstitial fibrosis, pulmonary edema and pulmonary hemorrhage (three each). Other findings included pleural effusion
TABLE 6

Comparison of selected features of nosocomial Legionnaires' disease from three reports

\begin{tabular}{|c|c|c|c|}
\hline Feature & Korvick et $a l^{*}$ & Kirby et $\mathrm{al}^{\dagger}$ & $\begin{array}{l}\text { Present } \\
\text { study }\end{array}$ \\
\hline Number studied & 65 & 20 & 55 \\
\hline Male:female ratio & $62: 3$ & $14: 6$ & $33: 22$ \\
\hline Mean age (years) & 59.2 & 52.3 & 58.6 \\
\hline Number died & $16(24.6)$ & $14(70)$ & $35(63.3)$ \\
\hline Immunosuppressed & $27(41.5)$ & $18(90)$ & $40(73)$ \\
\hline Malignancy & $19(29)$ & $7(35)$ & $16(29)$ \\
\hline Assisted ventilation & NS & NS & $33(60)$ \\
\hline Cough & $60(92)$ & $14(70)$ & $37(67)$ \\
\hline Chills & $50(77)$ & $6(30)$ & $17(31)$ \\
\hline Diarrhea & $30(47)$ & $3(15)$ & $12(22)$ \\
\hline Dyspnea & $23(36)$ & $7(35)$ & $35(64)$ \\
\hline Chest pain & $21(33)$ & $11(55)$ & $8(15)$ \\
\hline Hemoptysis & $22(34)$ & $6(30)$ & $1(2)$ \\
\hline Legionnella isolated & $5(8)$ & NS & $40(70)$ \\
\hline
\end{tabular}

Numbers in brackets refer to percentage; *Reference 20 ; Reference 21. NS Not stated

and pre-existing pneumonia (two each), and one each of bronchial stenosis and metastatic carcinoma.

When clinical and radiographic features were combined, the following patterns emerged: nonspecific pattern, 14 (30\%); lobar pneumonia, 11 (20\%); rapidly progressive pneumonia, eight (16\%); aspiration, three (6\%); pulmonary embolus, two (4\%); and multiple peripheral opacities, four (8\%). The authors were unable to determine a specific pattern due to pre-existing lung disease in eight (16\%). Examples of the various radiographic patterns are given in Figures 2 to 6. Figures 7 and 8 illustrate the clinical course and radiographic features of one patient.

Twenty-eight patients had acute and at least four week convalescent serum samples collected. Twenty-one $(75 \%)$ showed at least a fourfold rise in antibody titre.

\section{DISCUSSION}

There have been many reports of nosocomial Legionnaires' disease. Korvick and co-workers (19) reviewed 16 reports of nosocomial legionellosis published from 1965 to 1983. Only four of the reports described more than 40 patients. The mortality rate ranged from 17 to $66 \%$. The major underlying diseases were immunocompromised state, malignancy and chronic lung disease. Legionella was isolated from the environment in 14 of the 16 reports and in 12 of these 14 , isolation was from potable water. Korvick and Yu (20) in another report noted that surgical patients represent 23 to $50 \%$ of all patients with nosocomial Legionnaires' disease. Fifty-three per cent of the present patients had undergone surgery within the two weeks prior to the onset of nosocomial pneumonia.

Table 6 summarizes selected data from two other studies of nosocomial legionellosis $(21,22)$ so that ready 

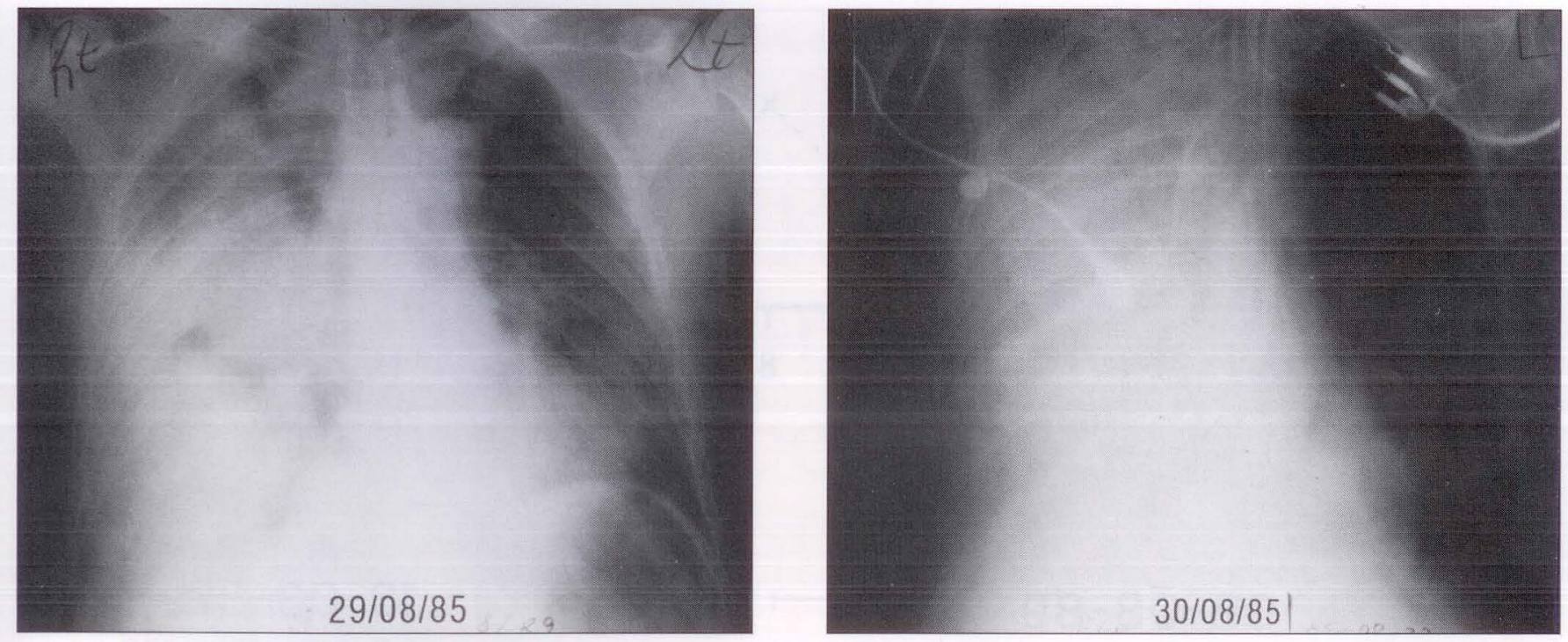

Figure 4) Chest radiographs showing consolidation of the entire right lung due to Legionella pneumophila
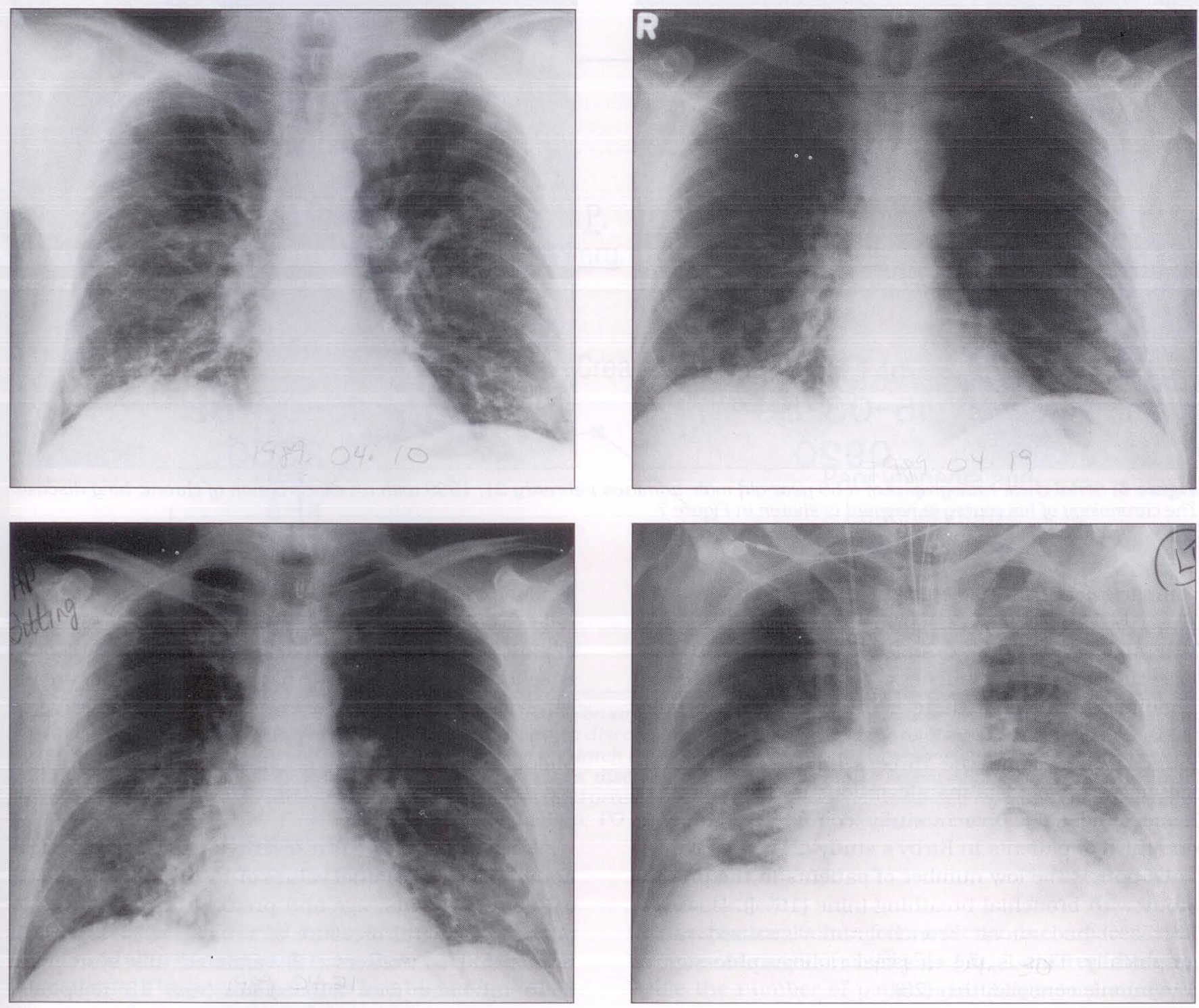

Figure 5) Serial chest radiographs of a patient with Pneumocystis carinii pneumonia. On April 21, 1989, the patient clinically deteriorated and Legionella pneumophila was isolated. This series illustrates the effect of underlying lung disease on the interpretation of change due to infection with $\mathrm{L}$ pneumophila 

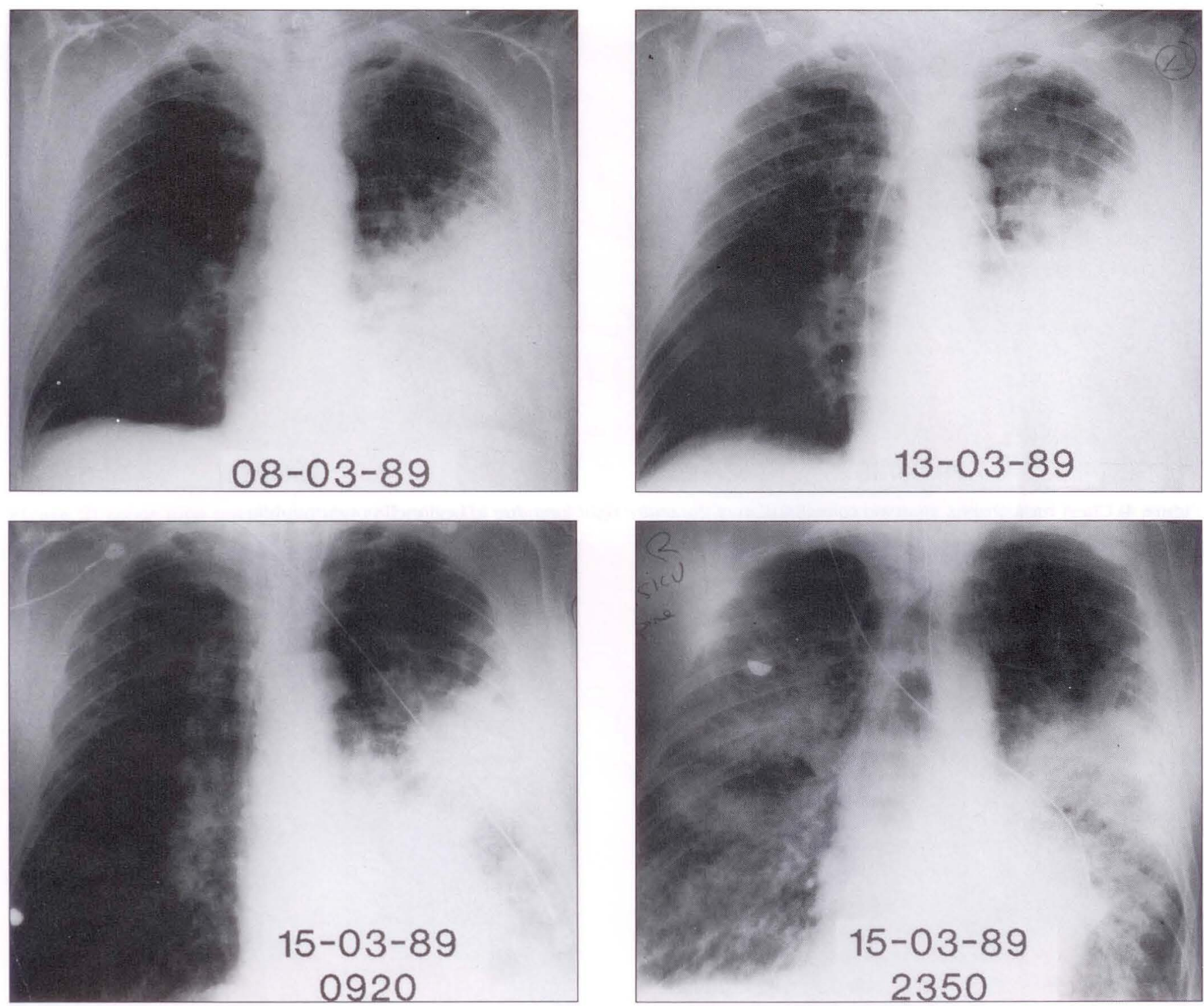

Figure 6) Serial chest radiographs of a 69-year-old male admitted February 21, 1989 with an exacerbation of chronic lung disease. The chronology of his course in hospital is shown in Figure 7

comparison can be made with the present patients. The study by Kirby et al (21) involved an outbreak in a Veterans' Hospital in Los Angeles, California; the other two studies involved patients with sporadic nosocomial Legionnaires' disease. There are differences in mortality rates and in the percentage of patients who were immunosuppressed in the three studies. A major difference in the clinical manifestations is the low rate of hemoptysis in the present study, compared with about one-third of patients in Kirby's study (21).

Of note is the low number of patients in the present study with bronchial breathing (nine [16\%]). However, $26(52 \%)$ had an air bronchogram visualized radiographically. This is the classical radiographic sign of pneumonic consolidation (23).

Nine of the present patients had positive blood cultures suggesting that at least $16 \%$ of patients had dual infections. Isolation of a variety of pathogens other than legionella from the sputum in most instances probably reflects colonization of the respiratory tract of seriously ill patients. Pneumocystis carinii, however, was responsible for pneumonia in the patient who had the organism in the respiratory secretion, and it is likely that at least some of the other pathogens also caused the pneumonia. It is equally possible that in some instances legionella may have been a colonizer and not a pathogen.

The APACHE II score is a severity of disease classification that uses the initial values of 12 routine physiological measurements, age and previous health status to provide a general measure of severity of disease (18). Knaus and co-workers (18) validated this system for 5815 intensive care admissions from 13 hospitals. While the maximum score possible is 71 , no patient has exceeded 55. A key finding in Knaus's study (18) was the significant increase in death rate for each five-point 

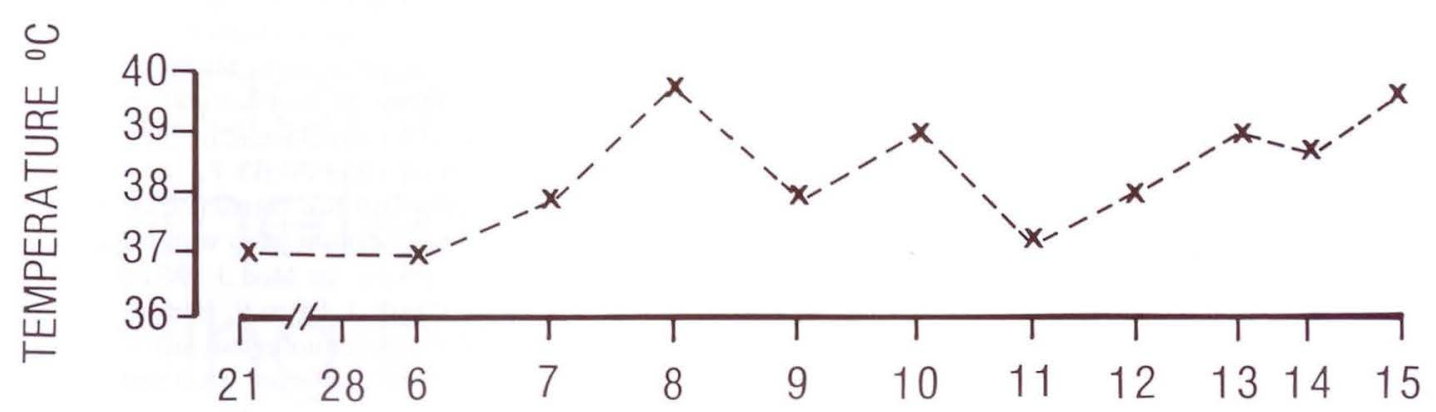
FEB MAR

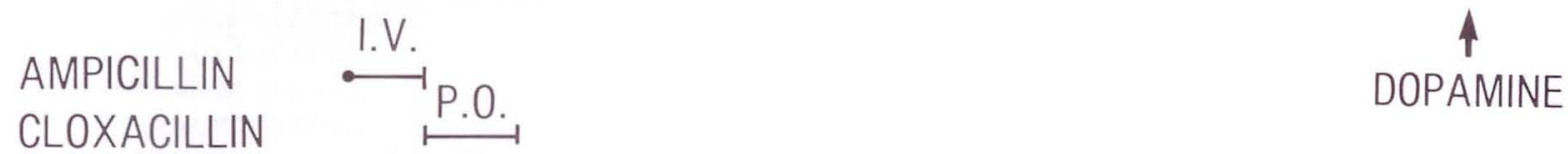

TOBRAMYCIN

CEPHAMANDOLE

ERYTHROMYCIN

SOLUMEDROL

RIFAMPIN

CEFTAZIDIME

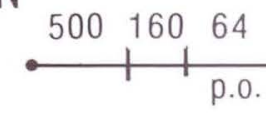

SOLUCORTEF
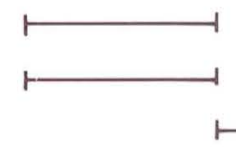

\section{0.}

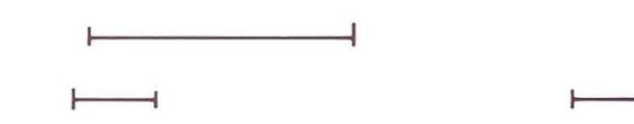

$\underline{S}$.

SPUTUM CULTURE aureus Mar.

BLOOD CULTURE

cult-
P.

aeru.

L. pneumophila 1+

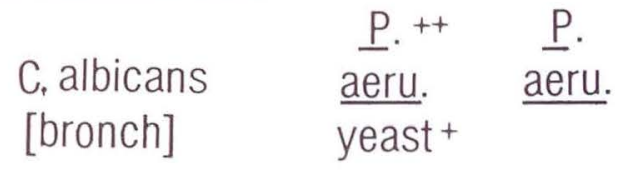

$1 / 4$ S. eppi

Creatinine normal until 14th

$1: 512$

Legionella titer

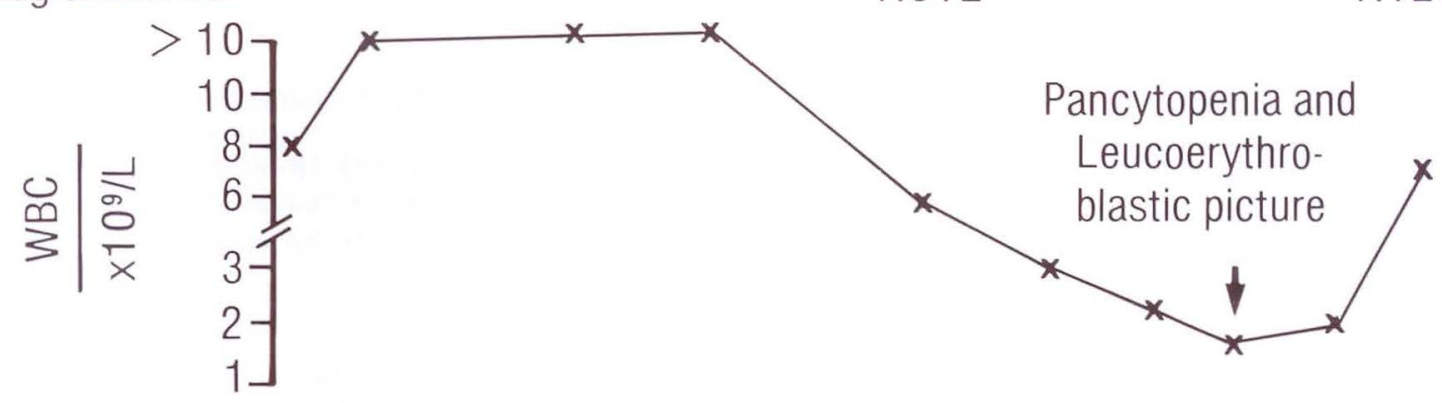

Figure 7) In-hospital course of a 69-year-old male admitted February 21, 1989. with an exacerbation of chronic lung disease. An admission chest radiograph showed only chronic obstructive lung disease. The patient became febrile on March 7. 1989. and Legionella pneumophila was isolated from a sputum sample obtained on March 9, 1989. The infectious disease consultant who saw the patient on March 9 made a clinical diagnosis of nosocomial Legionnaires' disease. At autopsy, there were severe emphysema, bilateral lobar pneumonia and bilateral microabscesses. Gram-positive cocci and yeast were seen on microscopic examination of the lungs. C Candida; IV Intravenous: L Legionella; P aeru Pseudomonas aeruginosa; PO Per ora (by mouth): S Staphylococcus; S epi Staphylococcus epidermidis: WBC White blood cell count

increase in score. In general, nonoperative patients had higher mortality rates at each score than did postoperative patients. The present patients had higher mortality rates in each interval than did patients with various diagnoses in the report by Knaus et al (18). This observation holds true even when the subset of their patients with respiratory failure from infection is compared with the present cases of nosocomial Legionnaires' disease. While the number of patients in the present study is small, it seems that a pneumonia-specific scoring system should be developed.

The radiographic manifestations of nosocomial 
Legionnaires' disease have been reported by a number of investigators $(21,22)$. However, they did not report on pre-existing lung disease. Fifty-eight per cent of the present patients had pre-existing disease, often to such an extent that the authors were unable to differentiate the changes due to legionella infection from the primary disease process. When the radiographic pictures were combined with the clinical data, three patterns emerged that were suggestive of nosocomial Legionnaires' disease: lobar opacity, rapidly progressive pneumonia and multiple peripheral opacities. However, these three patterns accounted for only $40 \%$ of cases. Thus, there is nothing to distinguish most cases of nosocomial Legionnaires' disease from other types of nosocomial pneumonia.

ACKNOWLEDGEMENTS: This research was supported by grant MT 10577 from the Medical Research Council of Canada. We thank Ms Rhonda Grandy, RN, for data collection and Ms Lisa Turner-Trottier for help with data processing. We are grateful to the staff of the respiratory microbiology laboratory for isolation of legionella.

\section{REFERENCES}

1. McDade JE, Shepard CC, Fraser DW, et al. Legionnaires' disease. Isolation of a bacterium and demonstration of its role in other respiratory disease. $\mathrm{N}$ Engl $\mathrm{J}$ Med 1977;297:1197-203.

2. Thacker SB, Bennett JV, Tsai T, et al. An outbreak in 1965 of severe respiratory illness caused by Legionnaires' disease bacterium. J Infect Dis 1978:238:512-9.

3. Brennen C, Vickers RM, Yu VL, Puntereri A, Yee CY. Discovery of occult legionella pneumonia in a long stay hospital: Results of prospective serological study. Br Med J 1987;295:306-7.

4. Muder RR, Yu VL, McClure J, et al. Nosocomial Legionnaires' disease uncovered in a prospective pneumonia study: Implications for under diagnosis. JAMA 1982:249:3184-92.

5. Yu VL, Beam TR, Lumish RM, et al. Routine culturing for legionella in the hospital environment may be a good idea: A three-hospital prospective study. Am J Med Sci 1987:30:97-9.

6. Marshal W, Foster RS, Winn W. Legionnaires' disease in renal transplant patients. Am J Surg Sci 1981:141:423.

7. Saravolatz L, Pohlod D, Helzer, et al. Legionella infection in renal transplant recipients. In: Thornsberry C, Balows A, Feeley JC, et al, eds. Legionella: Proceedings of the 2nd International Symposium, Washington: American Society for Microbiology, 1984:231-3.
8. Fliermans CB, Cheery WB, Orrison LH, Smith SJ, Tison DL, Pope DH. Ecological distribution of Legionella pneumophila. Appl Environ Microbiol 1981;41:9-16.

9. Joly JR, Brissinot M, Duchaine J, et al. Ecological distribution of legionellaceae in the Quebec city area. Can J Microbiol 1984;30:63-7.

10. Tobin JOH, Swann RA, Bartlett CLR. Isolation of Legionella pneumophila from water systems: Methods and preliminary results. Br Med J 1981;282:515-7.

11. Guiguet M, Pierre J, Brun P, Berthelot G, Gottot A, Gibert C, Valleron A. Epidemiological survey of a major outbreak of nosocomial legionellosis. Int J Epidemiol 1987; 16:466-71.

12. Palmer SR, Zamiri I, Ribeiro CD, Gajewska A. Legionnaires' disease cluster and reduction in hospital hot water temperatures. Br Med J 1986;292:1494-5.

13. Best M, Yu VL, Stout J, Goetz A, Muder RR, Taylor F. Legionellaceae in the hospital water supply. Epidemiological link with disease and evaluation of a method for control of nosocomial Legionnaires' disease and Pittsburgh pneumonia. Lancet 1983:307-10.

14. Helms CM, Massanari RM, Zeitler R, et al. Legionnaires' disease associated with a hospital water system: A cluster of 24 nosocomial cases. Ann Intern Med 1983:99:172-8.

15. Marrie TJ, MacDonald S, Clarke K, Haldane D. Nosocomial Legionnaires' disease - Lessons from a four-year prospective study. J Infect Cont 1991;19:79-85.

16. Cherry WB, Pittman B, Harris PP, Hebert GA, Thomason BM, Weaver RE. Detection of Legionnaires' disease bacteria by direct immunofluorescent staining. J Clin Microbiol 1981;14:298-303.

17. Wilkinson HW, Fikes BJ, Cruce D. Indirect immunofluorescence test for serodiagnosis of Legionnaires' disease: Evidence for serogroup diversity of Legionnaires' disease bacterial antigens and for multiple specificity of human antibodies. J Clin Microbiol 1979:9:379-83.

18. Knaus WA, Draper EA, Wagner DP, Zimmerman JE. APACHE II: A severity of disease classification system. Crit Care Med 1985;13:818-29.

19. Korvick JA, Yu VL, Fang G-D. Legionella species as hospital-acquired respiratory pathogens. Semin Respir Infect 1987;II:34-47.

20. Korvick JA, Yu VL. Legionnaires' disease: An emerging surgical problem. Ann Thorac Surg 1987;43:341-7.

21. Kirby BD, Snyder KM, Meyer RD, Finegold SM. Legionnaires' disease: Report of sixty-five nosocomially acquired cases and review of the literature. Medicine 1980;59:188-205.

22. Helms CM, Viner JP, Weisenburger DD. Chiu LC, Renner ED, Johnson W. Sporadic Legionnaires' disease: Clinical observations on 87 nosocomial and community-acquired cases. Am J Med Sci 1984:288:2-12.

23. Infectious diseases of the lungs. In: Fraser RG, Pare JA, Pare PD. Fraser RS, Genereux GP, eds. Diagnosis of Diseases of the Chest, 3rd edn. Toronto: WB Saunders. 1989:831. 


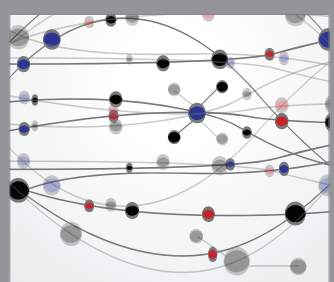

The Scientific World Journal
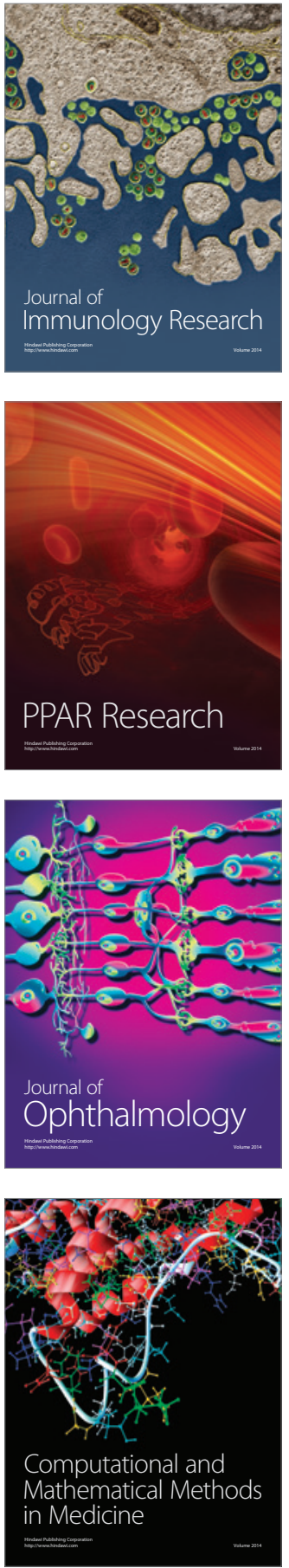

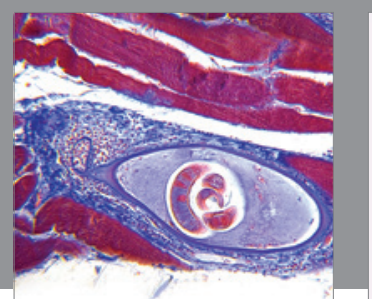

Gastroenterology Research and Practice

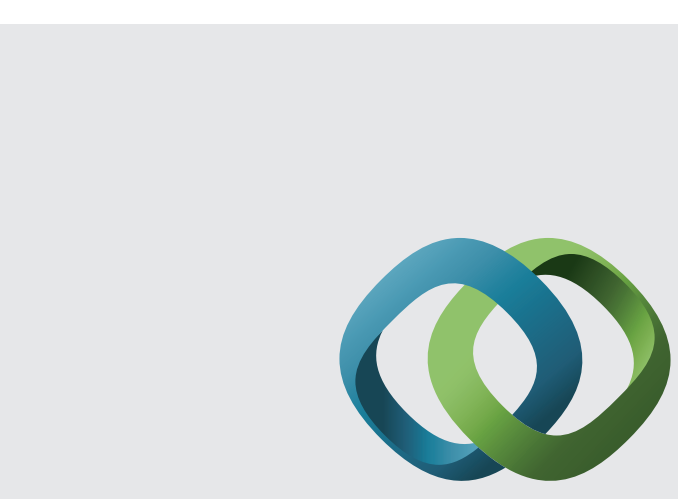

\section{Hindawi}

Submit your manuscripts at

http://www.hindawi.com
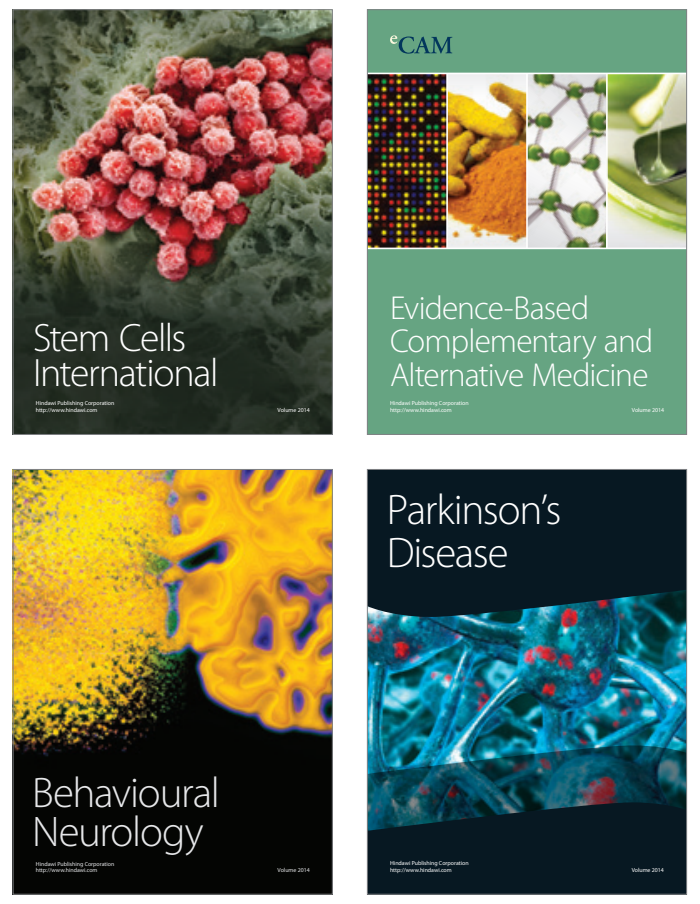
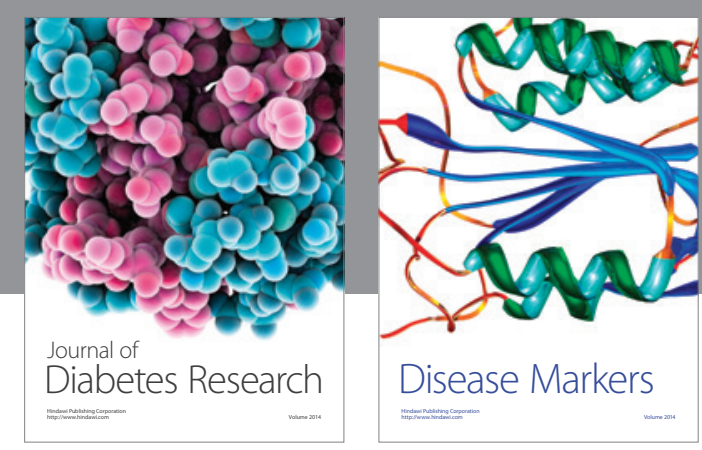

Disease Markers
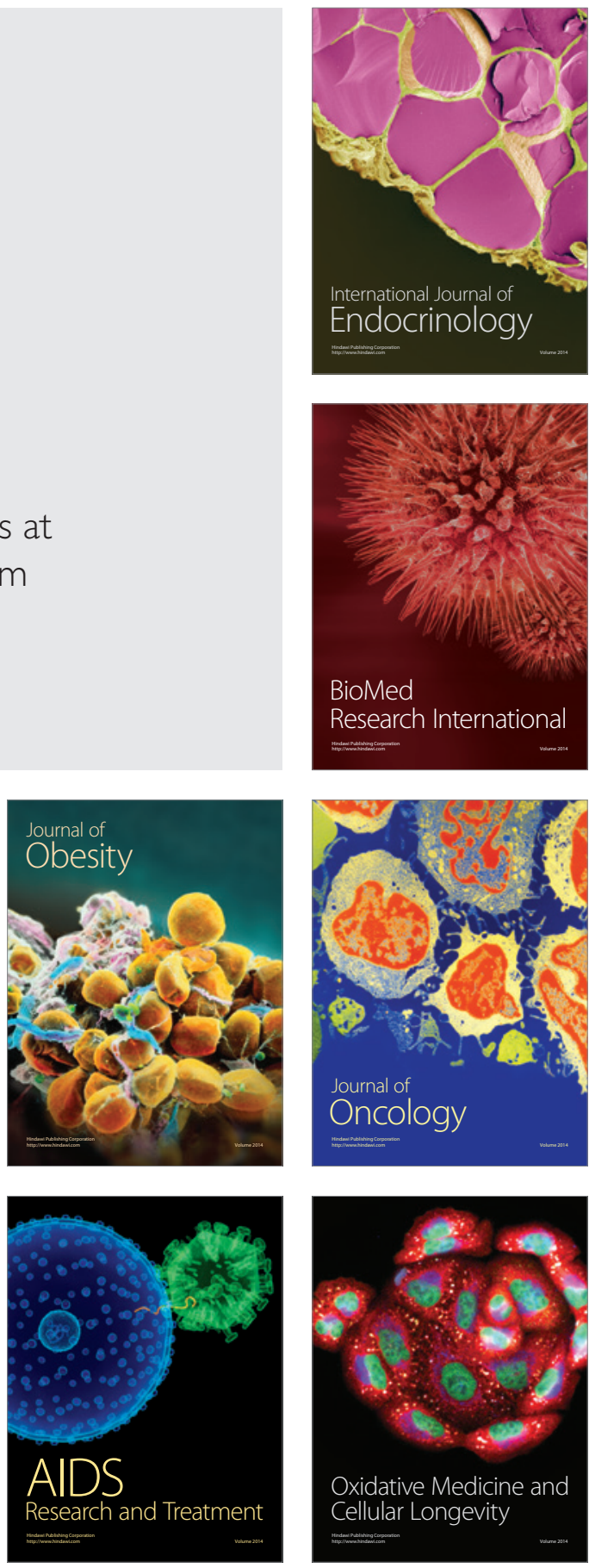